\title{
OPTIMAL ENERGY SOURCE FOR AN ENVIRONMENTALLY-FRIENDLY GO-KART
}

\author{
Piotr Zbigniew Filipek', Mariusz Ostrowski ${ }^{1}$ \\ 1 Faculty of Electrical Engineering and Computer Science, Lublin University of Technology, Lublin, Poland, \\ e-mail: piotr.filipek@pollub.pl
}

Received: 2016.08 .16

Accepted: 2016.09.26

Published: 2016.11.01

\begin{abstract}
A method for a sizing of an electromechanical battery for electrical go-kart was presented in the paper. The main goal of this research was to replace the internal combustion (IC) engine by an electric drive system taking into account the traction properties, on the one hand and the duration of operation on a single charge and the number of the battery life cycles on the other. The proposed method permits an entire depreciation of the price of the vehicle before the degradation of the battery occurs. The results of the study have been used to adjust the source for electric gokarts that will be mass produced.
\end{abstract}

Keywords: electrical vehicle, go-kart, optimal battery sizing, traction simulation

\section{INTRODUCTION}

The European Union's legislative work aimed at tightening environmental regulations and introducing fire safety regulations limit the operation of combustion vehicles indoors, forcing producers and users of karts to seek environmentally friendly solutions. (European Commission 2016). Among the solutions considered, the most attractive ones are karts with electric drive, the choice of which is affected by their well-known operational advantages, such as: no emissions, maximum starting torque, high dynamics, a wide range of speed control and quiet operation. While adjusting the electric drive motor to the kart is not a problem, the choice of the type and size of its power source is a challenge for designers.

The reason for this is the direct influence of the source parameters on both the driving dynamics and the price of the vehicle, which must be depreciated before the degradation of the battery occurs. Previous attempts to replace the internal combustion (IC) engine power in most cases did not give fully satisfactory results, considering the traction properties on the one hand and the duration of operation on a single charge and the number of the battery life cycles on the other. There are many commercially available electric go-kart solutions, but most of them have one of the three disadvantages:

- worse driving dynamics than comparable IC vehicles, which is mainly due to the excessive weight of the electrochemical batteries applied to ensure the operating time of a standard combustion kart,

- the dynamic comparable to the combustion version, but no guarantee of the expected operating time on a single charge,

- satisfactory driving dynamics while ensuring the necessary operating time, but the tradeoff is small battery durability, causing battery degradation before its payback time.

The selection of batteries is a difficult task due to the nature of the kart operation, much different from the motor car. In typical passenger vehicles, we have to deal with short periods of starting and acceleration characterized by high power demand, which are usually followed by long periods of driving at a speed with much lower power consumption. (Hae-Ryong Choi \& Gyu-Ha Choe 2010). In contrast, in a typical duty cycle of a kart we have an almost continuous dynamic state of alternating periods of acceleration and decelera- 
tion. (Heffernan et al. 2010). Therefore, the battery pack used in a go-kart is exposed to much higher discharging and charging currents, and should have a higher current (and thus capacity) rating. However, it should be remembered that its size (and thus, its weight) should not impair the driving dynamics and have a reasonable price for the application to be used commercially.

\section{SIMPLIFIED MODEL OF A KART}

The key issue in the selection of batteries is to develop a model of the vehicle taking into account its mass, friction and traction resulting from the kind of electric drive motor applied.

For the purpose of the research, a simulation model was developed in Matlab with the following simplifications (Filipek et al. 2015):

- the vehicle has a rigid body represented by the resultant moment of inertia reduced to the driving wheel;

- its movement is on a flat and even road;

- mechanical friction torque is proportional to the vehicle mass and speed;

- aerodynamic drag is proportional to the square of the speed and the butting face of the vehicle;

- the torque of the driving wheel is decreased by all the friction resistance to movement under consideration;

- the power consumed by the electrical motor is the sum of effective power (at the driving wheel) and its mechanical and electrical power losses;

- friction mechanical losses of the motor power are proportional to its angular velocity;

- power losses in the electrical circuit are proportional to the square of current (electromagnetic torque).

The research was performed for the go-kart with a BLDC motor with a rated power output of $5 \mathrm{~kW}$, a nominal voltage of $48 \mathrm{~V}$ and the rated speed of 4000rpm, which drove the rear axle of the kart through a toothed transmission belt with a gear ratio of 3 . The selected powertrain was designed to provide a driving dynamics of the vehicle with a total weight up to $200 \mathrm{~kg}$ (including the driver) not worse than a comparable kart with a combustion engine, which accelerates to $50 \mathrm{~km} / \mathrm{h}$ in $3.5 \mathrm{~s}$. To assure good dynamic parameters and high energy efficiency a vector control method was applied for the motor control. (Pillay \& Krishnan 1989; Kolano 2012).
Another essential element is the identification of the load profile during the operation on a single charge. For this purpose, it is necessary to analyse the driving technique and the course of the track. Development of the simulation work on the go-kart track is considered helpful in determining the nominal current source and its electrochemical capacity necessary for continuous operation at a given time.

In a typical duty cycle of a kart we have a period of intense acceleration on a straight line, followed by rapid braking before entering a turn and then again alternating periods of acceleration and deceleration. Therefore, a representation of all those operating states is necessary.

In the first stage, the straight-line movement of the vehicle was considered, in which the angular velocity of the wheels was proportional to the forward speed so it can be treated as a system with one-degree of freedom. Therefore, the mass of the vehicle and its moments of inertia are replaced with the equivalent value $I_{z}$ reduced to the driving wheel shaft terms.

The movement of the vehicle is described by the differential equation:

$$
\frac{d}{d t} \omega(t)=\frac{T_{w h e e l}(t)}{I_{z}}-\frac{c}{I_{z}} \omega^{2}(t), \quad 1 / \mathrm{s}^{2}
$$

where: $t$ is time,

$\omega$ is an angular velocity of the driving wheel,

$T_{\text {wheel }}$ is a driving torque of the wheel,

$I_{z}=0.042 \mathrm{kgm}^{2}$ is an equivalent moment of inertia reduced to a shaft of the driving wheel terms,

$c=1 / 2 C_{x} \cdot \rho \cdot S \cdot r^{3} N m s^{2}$ is an aerodynamic drag coefficient reduced to rotary motion, $C_{x}=0.5$ is an aerodynamic drag coefficient of the vehicle,

$S=0.7 \mathrm{~m}^{2}$ is a butting face of the vehicle, $\rho=1.168 \mathrm{~kg} / \mathrm{m}^{3}$ is a normal air density, $r=0.012 \mathrm{~m}$ is a radius of the wheel.

Sometimes, after acceleration there is a short time of driving on a straight line straight with a maximum constant angular speed of the wheel for a vehicle speed equal $50 \mathrm{~km} / \mathrm{h}$. In such a case of a steady state

$$
\omega(t)=\omega_{\max }=\text { const, } \quad 1 / \mathrm{s}
$$

the wheel driving torque compensates only the drag

$$
T_{\text {wheel }}(t)=c \cdot \omega^{2}(t), \quad \mathrm{Nm}
$$


Fast driving along a curvy road means moving with possibly the greatest speed along straight stretches, but reducing the speed before going into a sharp turn. There are some alternatives to slowing down: losing speed as a consequence of natural resistance to motion, using mechanical brakes or regenerative braking using an electrical motor.

For idle driving with motor turned-off the differential equation is

$$
\frac{d}{d t} \omega(t)=-\frac{c}{I_{z}} \omega^{2}(t), \quad 1 / \mathrm{s}^{2}
$$

The differential equation for regenerative braking can be written as

$$
\frac{d}{d t} \omega(t)=-\frac{c}{I_{z}} \omega^{2}(t)-\frac{k_{p}}{I_{z}} \omega(t), \quad 1 / \mathrm{s}^{2}
$$

where: $k_{P}=\eta^{2}$ is the coefficient of resistance to motion, assuming that electrical motor efficiency $\eta$ in regenerative and motor operating mode are equal.

When mechanical barkers are used for slowing the vehicle down, the motion can be described by

$$
\frac{d}{d t} \omega(t)=-\frac{c}{I_{z}} \omega^{2}(t)-T_{H}, \quad 1 / \mathrm{s}^{2}
$$

where: $T_{H}$ is maximum braking torque estimated on the basis of time needed to stop the vehicle moving with a certain speed.

Taking into account that motor losses are lower than the value of other vehicle losses, a simplified motor model was considered for the purpose of the battery sizing. Proportionality between a current of a DC source and a generated driving torque was assumed.

$$
i_{b a t}(t)=k_{M} T_{m o t}(t), \quad \mathrm{A}
$$

where: $i_{\text {bat }}$ represents a current of the electrochemical battery and $k_{M}$ is an exciting flux dependent coefficient of the electrical machine.

Motor mechanical losses were neglected while only electrical losses were taken as quadratic function of $i_{b a t}$. Then power delivered by the battery was calculated as:

$$
P_{b a t}(t)=P_{\text {input }}(t)+R_{E} i_{b a t}^{2}(t), \quad \mathrm{W}
$$

where: $P_{\text {input }}$ is a useful mechanical motor power (covering mechanical drag) and $R_{E} \cdot i_{b a t}{ }^{2}$ are electrical power losses, in which $R_{E}$ represents an equivalent resistance of motor windings and battery.

\section{BATTERY SELECTION AND SIZING}

Estimation of the electrochemical source was performed for the go-kart with the expected time of continuous driving on a single battery charge assumed to be 1 hour. (Hunicz et al. 2015). In assembling the source for the application in question, regarded as mass-critical and highly power demanding. (Lowe et al. 2010). LiFeMn electrochemical cells that have a high specific energy, specific power and a large number of life cycles were chosen. The rated voltage of the battery is determined by the nominal voltage of the applied driving motor and should not be lower in comparison to its value. The basis for ensuring battery life is the principle that the maximum current drawn by the drive should not exceed the limit value used for electrochemical batteries.

A nominal battery current was found by comparing battery nominal energy losses and an equivalent energy losses for a operation time, which would ensure keeping within the limit of acceptable losses (preventing an overheating) in cells at continuous load.

$$
R_{b a t} I_{N b a t}{ }^{2} \tau_{e k}=R_{b a t} \int_{0}^{\tau_{e k}} i_{b a t}^{2}(t) d t, \quad \mathrm{~W}
$$

where: $\tau_{e k}$ is an operation time on a single charge, $R_{b a t}$ is battery internal resistance,

$I_{\text {Nbat }}$ is rated current of the battery,

$i_{\text {bat }}$ is a value of the battery current for the instant $t$.

Thus, the rated current was calculated as follows:

$$
I_{N b a t}=\sqrt{\frac{\int_{0}^{t=\tau_{c k}} i_{b a t}{ }^{2}(t) d t}{\tau_{e k}}}, \quad \mathrm{~A}
$$

The theoretical energy capacity $E_{b a t}$ of the source was estimated by integrating over the time $\left(\tau_{e k}=1 \mathrm{~h}\right)$ a sum of electrical losses and power consumed by electric drive system $P_{\text {input }}$ required to cover the entire distance on a single charge in continuous operation.

$$
E_{\text {bat }}=\int_{t=0}^{t=\tau_{\text {ely }}}\left(P_{\text {input }}+R_{E} i_{\text {bat }}^{2}\right) d t, \quad \mathrm{~J}
$$

This value can be recalculated to the theoretical Coulombic capacity of the battery by dividing it by its rated voltage $U_{b a t}$ : 


$$
C C_{\text {batTeor }}=\frac{E_{b a t}}{U_{b a t}}, \quad \mathrm{Ah}
$$

In order to ensure sufficient life of the batteries, which is the number of life cycles allowing for the total depreciation of the entire vehicle, it is assumed that the discharge should be no more than $80 \%$ DOD (Depth of Discharge). Furthermore, according to the recommendations of the US ABC, in order to maintain the parameters of the source constant during the whole expected lifetime (up to battery replacement), the actual battery capacity was also increased by $30 \%$. (US ABC 2010; Lowe et al. 2010):

$$
C C_{\text {batMIN }}=1.3 \cdot C C_{\text {batTeor }} / 0.8,
$$

These calculations were performed for two driving techniques - the first using a regenerative braking and the second applying only mechanical braking. In practice, it is impossible to drive using only the mechanical- or regenerativebraking technique, since the final parameters of the source were averaged.
Results of computer simulations of one acceleration-braking cycle for the two driving techniques were shown at Figure 1 and Figure 2 where: a) $V$ - a vehicle speed, $T_{\text {wheel }}$ - a wheel driving torque; b) $T_{m o t}-$ an electromagnetic torque, $P_{\text {mot loss }}$ - motor losses, $P_{\text {input }}$ - power consumed by drive system; c) $i_{b a t}$ - a battery current, $P_{b a t}$ loss - battery power losses; d) $P_{b a t}-$ power and $E_{b a t}$ - energy delivered by the battery.

Computations based on equation (10) for a LiFeMn battery with a rated voltage of $48 \mathrm{~V}$ gave a minimal value of the battery nominal current of: - $I_{\text {Nbar }} \geq 50 \mathrm{~A}$ for a driving technique with mechanical-braking and

- $I_{N b a t} \geq 58 \mathrm{~A}$ for a driving technique with regenerative-braking.

It should be noticed, that a value of the current for a case of the regenerative-braking is bigger than for the other one because during this operation there is "no rest" for the source since a charging current generates additional energy losses. Considering a mixed-braking technique of driving, the battery current should be at least 54A.

a)
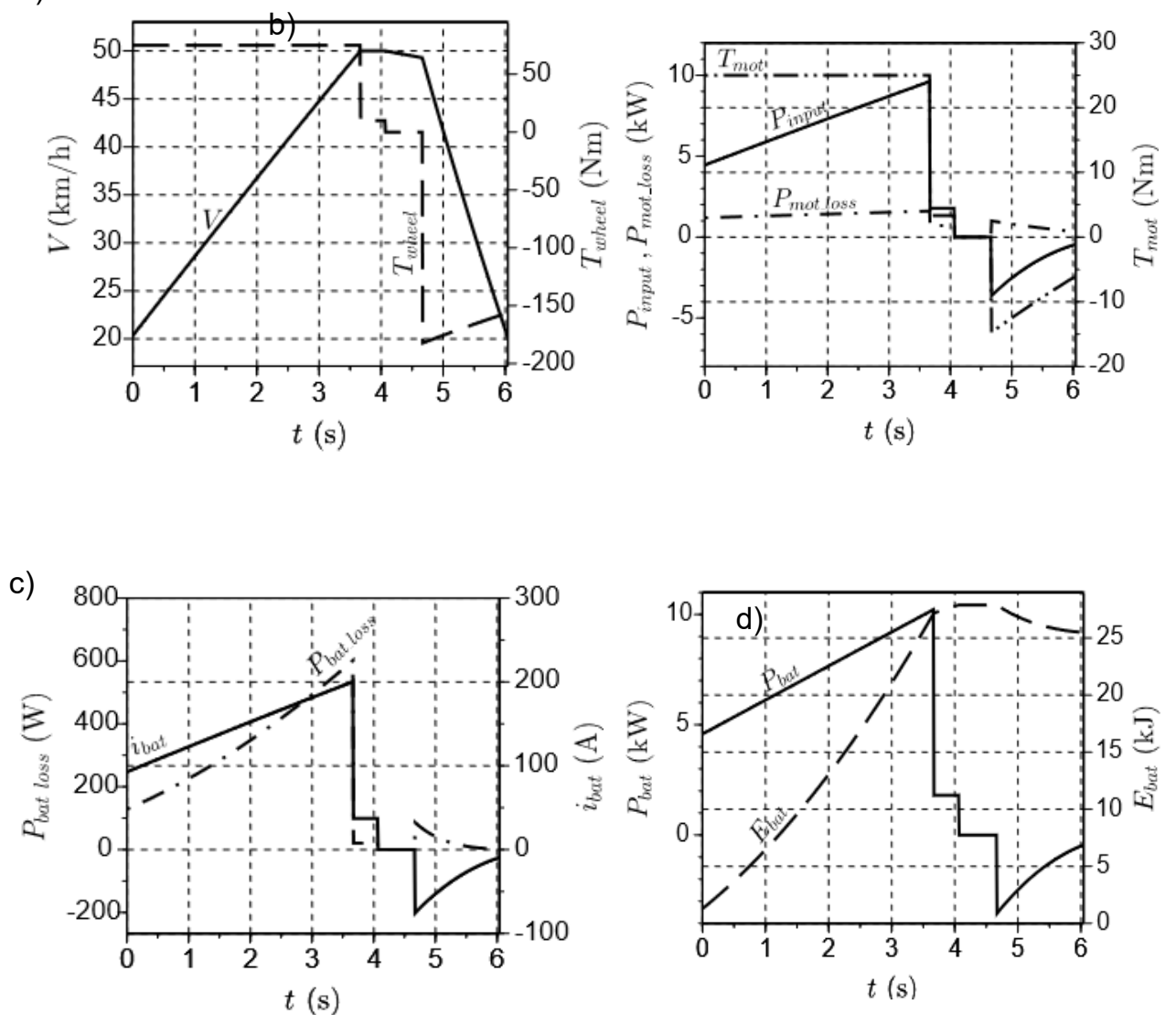

Figure 1. Simulation results for one acceleration-braking cycle of a go-kart operation using a regenerative-braking driving technique. 
Computer simulations indicated an actual minimal value of the battery Coulombic capacity for the operating time of $1 \mathrm{~h}$ on a single charge, which should be:

- $C C_{\text {NatMIN }} \geq 111.72 \mathrm{Ah}$ for driving technique with mechanical-braking and

- $C C_{\text {NatMIN }} \geq 94.74 \mathrm{Ah}$ for driving technique with regenerative-braking.

A driving applying the regenerative braking needs smaller capacity comparing to mechanical braking technique because of some energy savings made during a charging mode. Since the mixedbraking technique is usually used in practice, the rated value of the battery Coulombic capacity should be averaged and not lower than 103.23 Ah.

The final choice of a particular model of an electrochemical source should result from the economic analysis and be a tradeoff between the lifecycle and the depreciation of kart purchase price before the degradation of the battery.

\section{CONCLUSIONS}

The new European regulations concerning the indoor operation of go-karts force their users to replace the IC drives used in the vehicles with ecological solutions. Among the available karts with electric drive few models have the traction parameters comparable to their IC counterparts, while providing the life cycle necessary for depreciation in continuous operation for 1 hour.

The article proposes a selection procedure for an electrochemical battery in an electric kart. The choice of a battery nominal current is based on the equivalent losses method. Estimation of an actual Coulombic capacity needs an integration of a consumed and saved (in regenerative mode) energy during a whole operating time on one charge. Since in practice there is mixed-braking technique of a driving, these calculation should be performed for the operation applying a me-


Figure 2. Simulation results for one acceleration-braking cycle of a go-kart operation using a mechanical-braking driving technique. 
chanical and regenerative braking, and then final values have to be averaged.

The procedure used for the selection of the electrochemical power source for an electric kart assured optimised choice of its parameters, which resulted in continuous operation of the kart on a single charge. At the same time, the necessary traction dynamics of the vehicle was obtained and the assumed life of the source maintained. The results of the study have been used to adjust the power source for electric go-karts that will be mass produced by NABOR of Kraśnik, Poland.

\section{REFERENCES}

1. European Commission, 2016. Review of the EU Air Policy. http://ec.europa.eu/environment/air/review_air_policy.htm

2. Filipek P.Z., Kolano K., Ostrowski M. 2015. Low energy consumption control strategy for electrical vehicle, WZEE Conference, Kielce Poland (unpublished).

3. Hae-Ryong Choi \& Gyu-Ha Choe. 2010. A Multiobjective Parametric Optimization for PassengerCar Steering Actuator. IEEE Transactions on Industrial Electronics, 57(3), 900-908.
4. Heffernan B. \& Duke R. \& Zhang R. \& Gaynor P. \& Cusdin M. 2010. A go-cart as an electric vehicle for undergraduate teaching and assessment. Universities Power Engineering Conference (AUPEC), 20th Australasian, 1-6.

5. Hunicz J. \& Kolano K. \& Filipek P. \& Ostrowski M. 2015. Integracja elektrycznego systemu napędowego $\mathrm{z}$ systemem sterowania i akumulatorowym systemem zasilania w pojeździe typu gokart, Raport z prac badawczo-rozwojowych na zlecenie firmy NABOR, Lublin, Poland (unpublished).

6. Kolano K. 2012. Lift car doors drive system with hi-efficient BLDC drive. Przeglad Elektrotechniczny, 88(11B), 348-349.

7. Lowe M. \& Tokuoka S. \& Trigg T. \& Gereffi G. 2010. Lithium-Ion Batteries for Electric Vehicles: THE U.S. VALUE CHAIN., 5 October 2010, CGGC.

8. Pillay P. \& Krishnan R. 1989. Modeling, Simulation, and Analysis of Permanent-Magnet Motor Drives, Part I: The Permanent Magnet Synchronous Motor Drive, IEEE Transactions On Industry Applications, March -April 1989, Vol. 25, No. 2.

9. US ABC 2010. Development of advanced high-performance batteries for electric vehicle (EV) applications, United States Advanced Battery Consortium LLC. 